\title{
Erratum to: Regulation of hematopoietic development by ZBTB transcription factors
}

\author{
Takahiro Maeda ${ }^{1}$
}

Published online: 22 July 2016

C The Japanese Society of Hematology 2016

\section{Erratum to: Int J Hematol}

\section{DOI 10.1007/s12185-016-2035-x}

In the original publication of the article, Fig. 3B was pub-

lished incorrectly. The correct figure is given here.

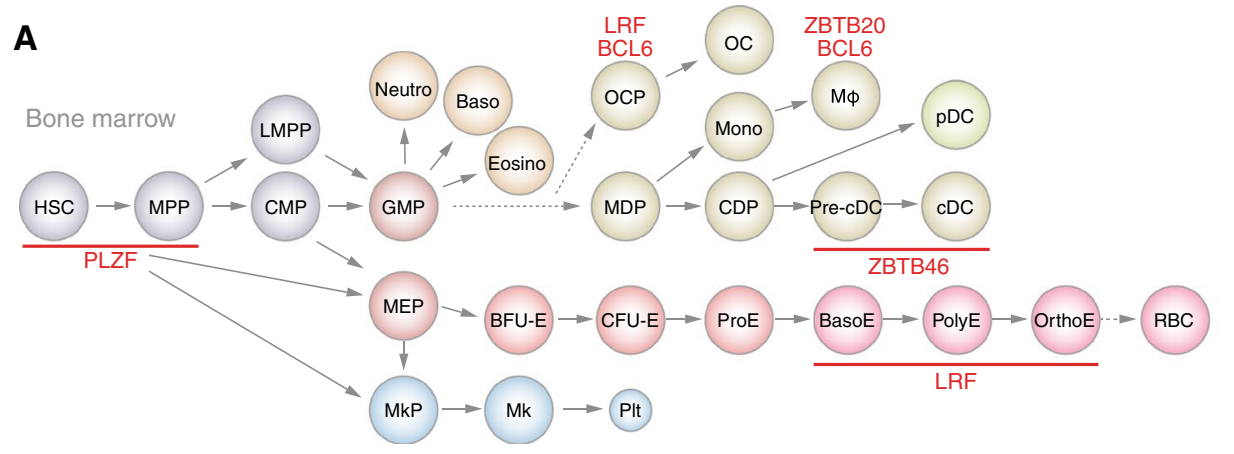

B

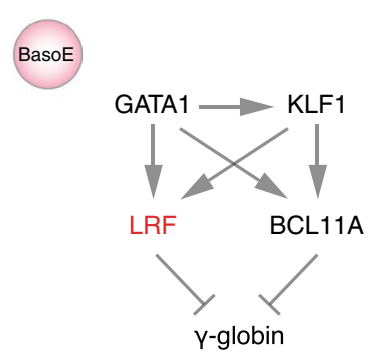

The online version of the original article can be found under doi:10.1007/s12185-016-2035-x.

Takahiro Maeda

tmaeda@partners.org

1 Division of Hematology, Department of Medicine, Brigham and Women's Hospital, Harvard Medical School,

One Blackfan Circle, Boston, MA 02115, USA 